03,12

\title{
Влияние углерода на электрические свойства объемных композитов на основе окиси меди
}

\author{
(C) Ю.Е. Калинин, М.А. Каширин, В.А. Макагонов, С.Ю. Панков, А.В. Ситников \\ Воронежский государственный технический университет, \\ Воронеж, Россия \\ E-mail: vlad_makagonov@mail.ru \\ (Поступила в Редакцию 19 сентября 2017 г. \\ В окончательной редакции 2 ноября 2017 г.)
}

\begin{abstract}
Исследовалось влияние углеродного наполнителя на электрическое сопротивление и термоэдс объемных композитов на основе оксида меди, полученных по керамической технологии методом горячего прессования. Установлено, что зависимости удельного электрического сопротивления от концентрации наполнителя характеризуются $S$-образными кривыми, типичными для перколяционных систем, при этом величина удельного электрического сопротивления убывает сильнее с увеличением содержания углерода по сравнению с уменьшением значения термоэдс, что сопровождается наличием максимума фактора термоэлектрической мощности в области порога протекания. Исследования температурных зависимостей удельного электрического сопротивления и термоэдс в области низких температур показали, что в диапазоне $240-300 \mathrm{~K}$ преобладающим механизмом электропереноса для всех исследованных композитов является прыжковый. Для композитов с нанокристаллической матрицей $\mathrm{CuO}$ при температурах ниже $240 \mathrm{~K}$ наблюдается прыжковая проводимость с переменной длиной прыжка по локализованным состояниям матрицы вблизи уровня Ферми, что связывается с проводимостью по межзеренным границам CuO. На основании анализа установленных экспериментальных закономерностей электропереноса предложена схематическая модель зонной структуры нанокристаллического $\mathrm{CuO}$ с углеродным наполнителем.
\end{abstract}

Работа выполнена при поддержке Минобрнауки в рамках государственного задания (проект № 3.1867.2017/4.6).

DOI: $10.21883 /$ FTT.2018.04.45674.272

\section{1. Введение}

Твердотельные термоэлектрические преобразователи энергии имеют ряд преимуществ перед традиционными электрическими генераторами и охладителями: простота конструкции, отсутствие движущихся частей, бесшумность работы, высокая надежность, возможность миниатюризации без потери эффективности, которая в существенной степени зависит от термоэлектрических материалов. В 90-е годы XX столетия было предложено несколько принципиально новых идей по повышению термоэлектрической добротности $[1,2]$. К этим идеям, прежде всего, относится использование низкоразмерных структур: тонких пленок $[3,4]$, сверхрешеток [3,5], нитевидных кристаллов [6], наноразмерных структур $[7,8]$, квантовых ям $[9,10]$, квантовых проволок $[11,12,13,14]$ и др.

Одной из важнейших особенностей физических свойств гетероструктур и систем пониженной размерности, приводящих к увеличению термоэлектрической добротности, является понижение теплопроводности за счет рассеяния фононов на поверхностях и гетерограницах. Первые исследования проводились на регулярных структурах (сверхрешетках и структурах с квантовыми ямами или проволоками), свойства которых легче поддаются теоретическому описанию, но в последнее время большой интерес вызывают более простые в производстве и дешевые композиты.
Оксиды меди являются перспективными термоэлектрическими материалами, обладающими высоким коэффициентом Зеебека $(S \sim 1000 \mu \mathrm{V} / \mathrm{K})$, однако низкой электропроводностью, что отрицательно сказывается на термоэлектрической добротности материала. Увеличение электрической проводимости при введении в оксиды меди проводящих наполнителей позволит повысить добротность таких систем.

Уменьшение теплопроводности - не единственное следствие введения нановключений в термоэлектрический материал: в нанокомпозитах могут изменяться процессы распространения и рассеяния не только фононов, но и электронов, в связи с чем изучение явлений электропереноса в гетерогенных наноструктурах является важной задачей как прикладного, так и фундаментального назначения.

Настоящая работа посвящена изучению влияния углеродного наполнителя (УН) на термоэдс и электрическую проводимость объемных композитов на основе оксидов меди.

\section{2. Образцы. Методика эксперимента}

Образцы композитов оксид меди - углеродный наполнитель $\left(\mathrm{Cu}_{n} \mathrm{O}-\mathrm{УH}(n=1,2)\right)$ были получены по керамической технологии методом горячего одностороннего прессования на воздухе при давлении $500 \mathrm{MPa}$ 
Таблица 1. Способы смешивания шихты и исходные компоненты, использованные при получении объемных композитов $\mathrm{Cu}_{n} \mathrm{O}-\mathrm{yH}$

\begin{tabular}{c|c|c|c}
\hline Композит & $\begin{array}{c}\text { Материал } \\
\text { матрицы }\end{array}$ & $\begin{array}{c}\text { Материал } \\
\text { наполнителя }\end{array}$ & $\begin{array}{c}\text { Способ } \\
\text { смешивания } \\
\text { компонентов }\end{array}$ \\
\hline$\left(\mathrm{Cu}_{2} \mathrm{O}_{\text {micro }}-\mathrm{УHM}\right)_{\mathrm{DBM}}$ & $\mathrm{Cu}_{2} \mathrm{O}_{\text {micro }}$ & УНM & DBM \\
$\left(\mathrm{CuO}_{\text {nano }}-\mathrm{УHM}\right)_{\mathrm{WBM}}$ & $\mathrm{CuO}_{\text {nano }}$ & УНM & WBM \\
$\left(\mathrm{CuO}_{\text {nano }}-\mathrm{УHB}\right)_{\mathrm{WBM}}$ & $\mathrm{CuO}_{\text {nano }}$ & УНВ & WBM \\
$\left(\mathrm{CuO}_{\text {nano }}-\mathrm{УHB}\right)_{\mathrm{USM}}$ & $\mathrm{CuO}_{\text {nano }}$ & УНВ & USM
\end{tabular}

Таблица 2. Результаты анализа фазового состава матрицы объемных композитов $\mathrm{Cu}_{n} \mathrm{O}-\mathrm{УH}(n=1,2)$

\begin{tabular}{c|c|c|c}
\hline \multirow{2}{*}{ Композит } & \multicolumn{3}{|c}{ Содержание фазы, mass\% } \\
\cline { 2 - 4 } & $\mathrm{Cu}_{2} \mathrm{O}$ & $\mathrm{CuO}$ & $\mathrm{Cu}$ \\
\hline$\left(\mathrm{Cu}_{2} \mathrm{O}_{\text {micro }}-\mathrm{УHM}\right)_{\text {DвM }}$ & 89.4 & 9.3 & 1.3 \\
$\left(\mathrm{CuO}_{\text {nano }}-\mathrm{УHM}\right)_{\text {WBM }}$ & 41.8 & 58.2 & 0 \\
$\left(\mathrm{CuO}_{\text {nano }}-\mathrm{УHB}\right)_{\text {WBM }}$ & 23.8 & 75.3 & 0.9 \\
$\left(\mathrm{CuO}_{\text {nano }}-\mathrm{УHB}\right)_{\text {USM }}$ & 3.3 & 96.1 & 0.6 \\
Исходный $\mathrm{Cu}_{2} \mathrm{O}_{\text {micro }}$ & 89 & 9.2 & 1.8 \\
Исходный $\mathrm{CuO}_{\text {nano }}$ & 15.6 & 83.2 & 1.2
\end{tabular}

и температуре $375^{\circ} \mathrm{C}$. В качестве материала матрицы композитов $\mathrm{Cu}_{n} \mathrm{O}-\mathrm{УН}$ использовались порошки оксидов меди $\mathrm{Cu}_{2} \mathrm{O}$ (чда, ТУ 5-09-765-95) $\left(\mathrm{Cu}_{2} \mathrm{O}_{\text {micro }}\right)$ и наноразмерный порошок оксида меди $\mathrm{CuO}\left(\mathrm{CuO}_{\text {nano }}\right)$, полученный методом электрического взрыва медного проводника в атмосфере кислорода (ООО „Передовые порошковые технологии“ г. Томск). Активным наполнителем служили углеродные нановолокна „ТАУНИТ“ (УНВ), синтезированные газопиролитическим методом [15], и углеродный наноматериал, полученный размолом высокопрочной высокомодульной углеродной ленты ЛУ-3 в энергонапряженной шаровой мельнице (УНМ) [16].

Смешивание исходных компонентов осуществлялось тремя способами: в планетарной шаровой мельнице „сухим способом“ в течение 5 h (DBM), в энергонапряженной планетарной мельнице АГО-3 „мокрым“ способом в этиловом спирте технической чистоты (WBM), ультразвуковым диспергированием в этиловом спирте (USM).

Способы смешивания шихты и изученные комбинации матричного материала и наполнителя представлены в табл. 1. После диспергирования различными способами смесь просушивалась при температуре $350 \pm 5 \mathrm{~K}$ до полного выпаривания спирта и компактировалась в брикеты размером $28 \times 34 \times 5 \mathrm{~mm}^{3}$ под давлением $50-100 \mathrm{MPa}$ при комнатной температуре. Затем образец помещался в горячую пресс-форму, нагревался до температуры прессования $(650 \mathrm{~K})$, выдерживался в течение 5 min для выравнивания тепловых потоков, после чего к образцу прикладывалось давление $500 \mathrm{MPa}$. Выдержка под давлением составляла $15 \mathrm{~min}$. После извлечения из пресс- формы образцы охлаждались на спокойном воздухе до комнатной температуры.

Для анализа фазового состава полученных композитов были проведены рентгеноструктурные исследования на рентгеновском дифрактометре Bruker D2 Phaser. Обработка результатов осуществлялась программными средствами Bruker DIFFRAC EVA 3.0 с применением базы данных PDF2012 и TOPAS 4.2. Фазовый состав оксидной матрицы композитов $\mathrm{Cu}_{n} \mathrm{O}-\mathrm{УH}(n=1,2)$ изменялся в зависимости от способа смешивания исходных компонентов (табл. 2), что особенно сильно заметно при использовании энергонапряженной планетарной мельницы и может объясняться восстановлением оксидов меди этанолом в процессе диспергирования. Корреляция между фазовым составом оксидной матрицы и содержанием углеродного наполнителя отсутствовала. Увеличение содержания $\mathrm{CuO}$ в композитах $\left(\mathrm{CuO}_{\text {nano }}-\mathrm{УHB}\right)_{\text {USM }}$ вероятно обусловлено окислением $\mathrm{Cu}_{2} \mathrm{O}$ и $\mathrm{Cu}$ до предельного оксида $\mathrm{CuO}$ кислородом воздуха в процессе прессования.

Для анализа равномерности распределения наполнителя в оксидной матрице были проведены исследования морфологии поверхностей свежих сколов композитов $\mathrm{Cu}_{n} \mathrm{O}-\mathrm{УH}(n=1,2)$ на растровом электронном микроскопе (РЭМ) ZEISS EVO MA 10. Анализ структуры полученных композитов показал, что частицы УН находятся в плотной, хорошо спеченной оксидной матрице в виде достаточно крупных агломератов. Для композитов $\left(\mathrm{Cu}_{2} \mathrm{O}_{\text {micro }}-\mathrm{УHM}\right)_{\text {DвM }}$ анализ показал наличие поликристаллической структуры образцов со средним размером кристаллов $\mathrm{Cu}_{2} \mathrm{O} \sim 5 \mu \mathrm{m}$, а агломератов УНМ $<1 \mu \mathrm{m}$. По мере роста массовой доли углерода в образцах, растет количество таких агломератов, а их размер практически не изменяется. Следует заметить, что агломераты УН преимущественно располагались на границах зерен $\mathrm{Cu}_{2} \mathrm{O}$ и при 5 mass\% углеродный наполнитель образует проводящие каналы в виде лабиринтной структуры.

Средний размер частиц $\mathrm{CuO}$ в композитах с матрицей $\mathrm{CuO}_{\text {nano }}$ составлял 50-100 nm. Исследования поверхностей скола композитов $\left(\mathrm{CuO}_{\text {nano }}-\mathrm{VHB}\right)_{\text {USM, }}$, полученных ультразвуковым смешиванием, показали, что размер самых крупных агломератов УНВ составляет $\sim 60-80 \mu \mathrm{m}$. При более высоком разрешении на поверхности скола в оксидной матрице можно различить единичные волокна (рис. 1).

Измерения электрического сопротивления проводились методом амперметра-вольтметра на постоянном токе при помощи цифрового мультиметра АКИП В7-78/1, позволяющего измерять электрическое сопротивление в диапазоне от 0.1 до $10^{9} \mathrm{Ohm}$. Зависимости термоэдс композитов от концентрации углерода получены посредством измерения каждого образца при комнатной температуре методом горячего зонда. Материалом холодного и горячего зондов служила серебряная проволока чистотой $99.99 \%$. Температурные зависимости термоэдс измерены по дифференциальной методике. Исследования температурных зависимостей электрического со- 


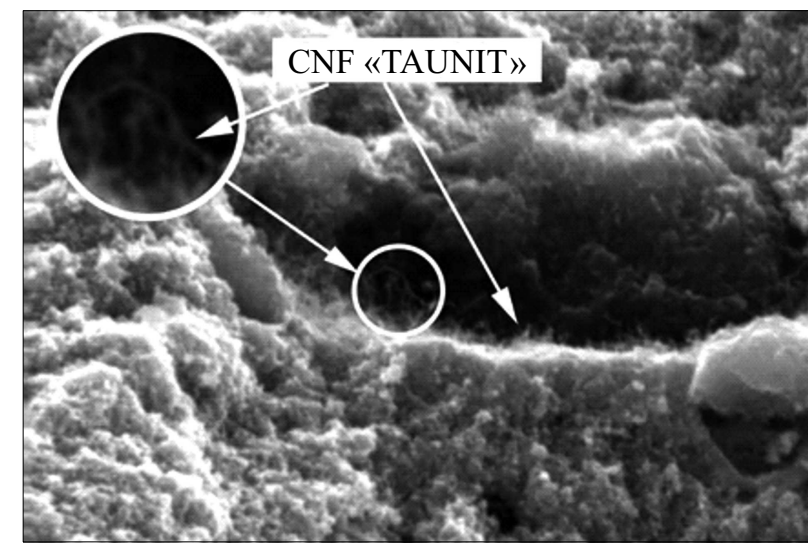

$2 \mu \mathrm{m}$

Рис. 1. РЭМ микрофотографии поверхности скола композита $\left(\mathrm{CuO}_{\text {nano }}-\text { УНB }\right)_{\text {usm }}$ с содержанием 5 mass\% УНВ.

противления и термоэдс в интервале $80-300 \mathrm{~K}$ проводились с помощью измерительной ячейки, помещенной в криостат, охлаждаемый жидким азотом. Рабочий объем криостата откачивался до остаточного давления $\sim 10^{-2}$ Torr. Увеличение температуры с постоянной скоростью осуществлялось с помощью двух резистивных нагревателей. Для исследования температурной зависимости термоэдс поддерживался градиент температуры $10-15 \mathrm{~K}$, обеспечиваемый подачей различных напряжений от двух одинаковых источников постоянного тока к нагревателям.

\section{3. Результаты эксперимента и их обсуждение}

3.1. Влияние концентрации и типа углеродного наполнителя на электрические свойства композитов $\mathrm{Cu}_{n} \mathrm{O}-\mathrm{УH}(n=1,2)$ при комнатной темпе ратуре. На рис. 2 приведены зависимости удельного электрического сопротивления $(\rho)$ (рис. 2, $a)$ и термоэдс $(S)$ (рис. 2,b) от доли углеродного наполнителя для исследованных композитов. Полученные зависимости были измерены при комнатной температуре и имеют $S$-образный вид, характерный для перколяционных систем $[17,18]: \rho$ и $S$ уменьшаются с увеличением содержания более электропроводящей фазы - углеродного наполнителя. Знак термоэдс для всех композитов положительный, что указывает на дырочный тип проводимости полученных композитов.

Проанализируем полученные результаты в зависимости от типа, дисперсности матрицы и наполнителя, а также способа смешивания углеродного наполнителя и порошков оксидов меди.

Зависимости удельного электрического сопротивления и термоэдс для композитов $\left(\mathrm{Cu}_{2} \mathrm{O}_{\text {micro }}-\text { УНМ }\right)_{\text {DвM }}$ (кривые 1, рис. 2) имеют точку перегиба при концентрации углеродного наполнителя $\mathrm{C}=2.5-3$ mass\%.
Если определить порог протекания как середину участка наиболее значительного уменьшения $\rho$ и $S$ с ростом содержания УН, то для композита $\left(\mathrm{Cu}_{2} \mathrm{O}_{\text {micro }}-\mathrm{УHM}\right)_{\text {DBM }}$ он составил $\sim 3.5$ mass $\%$, и при концентрации УНМ более 3.5 mass \% термоэлектрические свойства определяются углеродным наполнителем.

Анализ представленных зависимостей показал, что до порога протекания добавление УНМ приводит к более существенному уменьшению удельного электрического сопротивления по сравнению с изменением термоэдс. Так, введение 2.5 mass\% углеродного наполнителя приводит к понижению удельного электрического сопротивления композитов примерно на 2 порядка величины по сравнению с чистым $\mathrm{Cu}_{2} \mathrm{O}$ (с 23.6 до $0.54 \Omega \cdot \mathrm{m}$ ), в то время как термоэдс уменьшается лишь на $22 \%$ (с 767 до $600 \mu \mathrm{V} / \mathrm{K})$.

Замена матрицы на наноразмерную $\mathrm{CuO}$ должна была привести к более равномерному распределению углеродного наполнителя в матрице оксида меди и смещению порога протекания в сторону меньших концентраций УНМ. Значения $S$ композитов
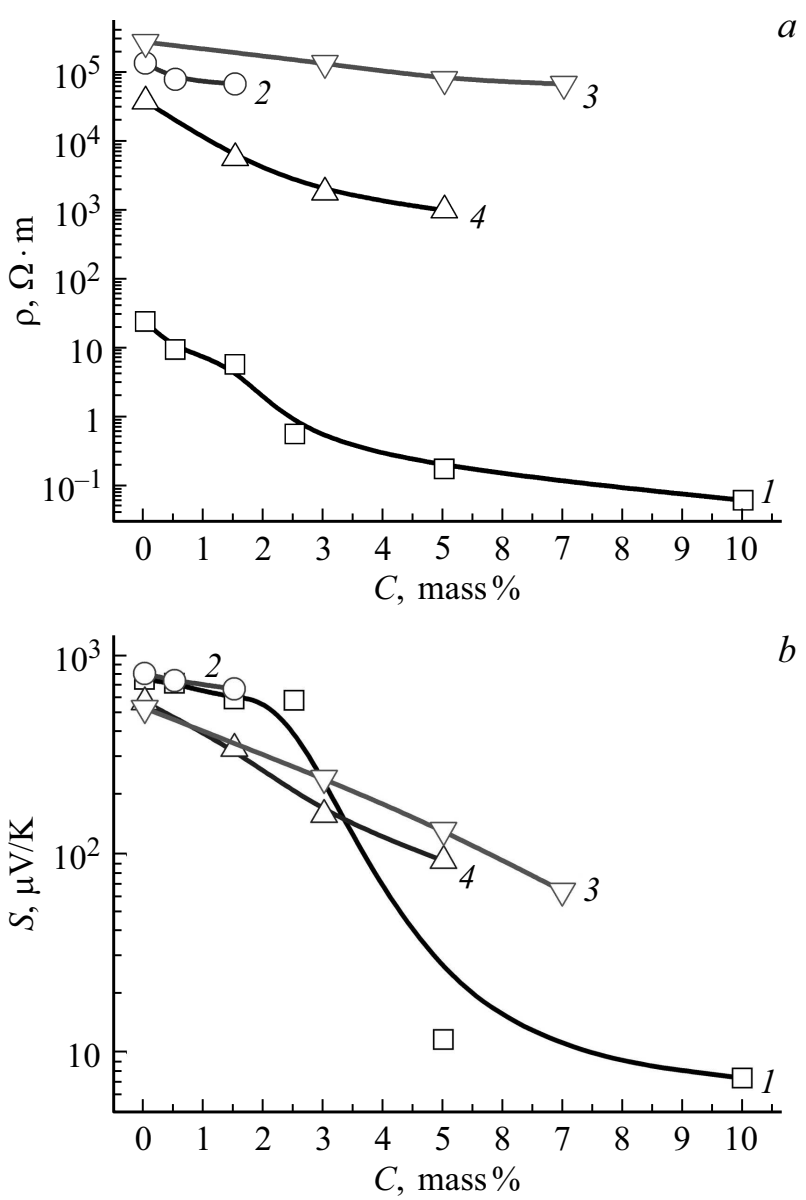

Рис. 2. Зависимости удельного электрического сопротивления $(a)$ и термоэдс $(b)$ от содержания углеродного наполнителя для композитов оксид меди $\mathrm{Cu}_{n} \mathrm{O}-\mathrm{УН}(n=1,2)$ : $1-\left(\mathrm{Cu}_{2} \mathrm{O}_{\text {micro }}-\mathrm{УHM}\right)_{\text {DBM }} ; 2-\left(\mathrm{CuO}_{\text {nano }}-\mathrm{YHM}\right)_{\text {WBM }}$; $3-\left(\mathrm{CuO}_{\text {nano }}-\mathrm{YHB}\right)_{\mathrm{WBM}} ; 4-\left(\mathrm{CuO}_{\text {nano }}-\mathrm{YHB}\right)_{\mathrm{USM}}$. 


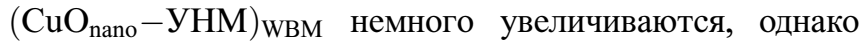
использование более высокоомного оксида $\mathrm{CuO}$ приводит к значительному (на 4 порядка величины) росту $\rho$ в области концентраций углерода до 1.5 mass\% (кривые 2, рис. 2,a) в сравнении со значениями для композита $\left(\mathrm{Cu}_{2} \mathrm{O}_{\text {micro }}-\mathrm{УHM}\right)_{\text {DBM. }}$. Значения $\rho$ и $S$ для образца $\mathrm{CuO}_{\text {nano }}$ без наполнителя составили $1.37 \cdot 10^{5} \Omega \cdot \mathrm{m} \quad$ и $\quad 822 \mu \mathrm{V} / \mathrm{K} \quad$ соответственно. При добавлении УНМ в количестве $1.5 \mathrm{mass} \%$ наблюдается уменьшение как величины удельного электрического сопротивления до $6.8 \cdot 10^{4} \Omega \cdot \mathrm{m}$ (почти на порядок), так и термоэдс до $686 \mu \mathrm{V} / \mathrm{K}$ (примерно на $17 \%$ ). Смещение порога протекания при этом не произошло, а все полученные образцы можно отнести к допороговой области концентраций углеродного наполнителя.

Известно, что если частицы проводящего наполнителя будут обладать большой величиной отношения длины к размерам сечения, известного как аспектное отношение, то порог протекания композита из непроводящей электрический ток матрицы с таким наполнителем лежит в области небольших концентраций последнего [19]. С целью проверки данного предположения были получены композиты $\left(\mathrm{CuO}_{\text {nano }}-\mathrm{VHB}\right)_{\mathrm{wBM}}$, где в качестве наполнителя использовались УНВ „Таунит“, обладающие наружным диаметром $10-60 \mathrm{~nm}$ и длиной более $2 \mu \mathrm{m}$. Однако значения удельного электрического сопротивления композита $\left(\mathrm{CuO}_{\text {nano }}-\mathrm{УHB}\right)_{\mathrm{WBM}}$ (кривая 3, рис. 2,a) возросли в сравнении с композитами $\left(\mathrm{CuO}_{\text {nano }}-\mathrm{УHM}\right)_{\text {Wвм }}$ (кривая 2, рис. $\left.2, a\right)$ для всего изученного диапазона концентраций углерода, а термоэдс понизилась. Несмотря на достаточно сильное изменение величины удельного электрического сопротивления с увеличением концентрации углеродного наполнителя (c $1.37 \cdot 10^{5}$ до $6.7 \cdot 10^{4} \Omega \cdot \mathrm{m}$ при изменении $\mathrm{C}$ от 0 до $7 \mathrm{mass} \%)$, порог протекания в данной системе не наблюдается. Данный эффект может являться следствием измельчения и частичной деструкции УНВ в процессе смешивания шихты в энергонапряженной мельнице. Чтобы избежать размола УНВ при диспергировании был применен метод ультразвукового смешивания. Кроме того, подобный способ приготовления образцов позволяет избежать механохимического воздействия на оксидную матрицу, которое заключается прежде всего в изменении соотношения между фазами $\mathrm{CuO}, \mathrm{Cu}_{2} \mathrm{O}$ и $\mathrm{Cu}$ (табл. 2).

При использовании ультразвукового диспергирования значения термоэдс в сравнении с полученными при механическом смешивании практически не изменились (кривая 4 и 3 , рис. $2, b$ для композитов $\left(\mathrm{CuO}_{\text {nano }}-\mathrm{YHB}\right)_{\text {USM и }}\left(\mathrm{CuO}_{\text {nano }}-\text { УНB }\right)_{\text {WBM }}$ соответственно), однако при этом были получены наименьшие среди композитов с матрицей $\mathrm{CuO}_{\text {nano }}$ значения удельного электрического сопротивления (кривые 2, 3, 4, рис. 2,a). Так же как и для всех остальных составов добавление углеродного наполнителя приводит к понижению удельного электрического сопротивления композитов $\left(\mathrm{CuO}_{\text {nano }}-\mathrm{VHB}\right)_{\text {USM }}$ и термоэдс. Так, введение 3 mass\% углеродного наполнителя понижает $\rho$
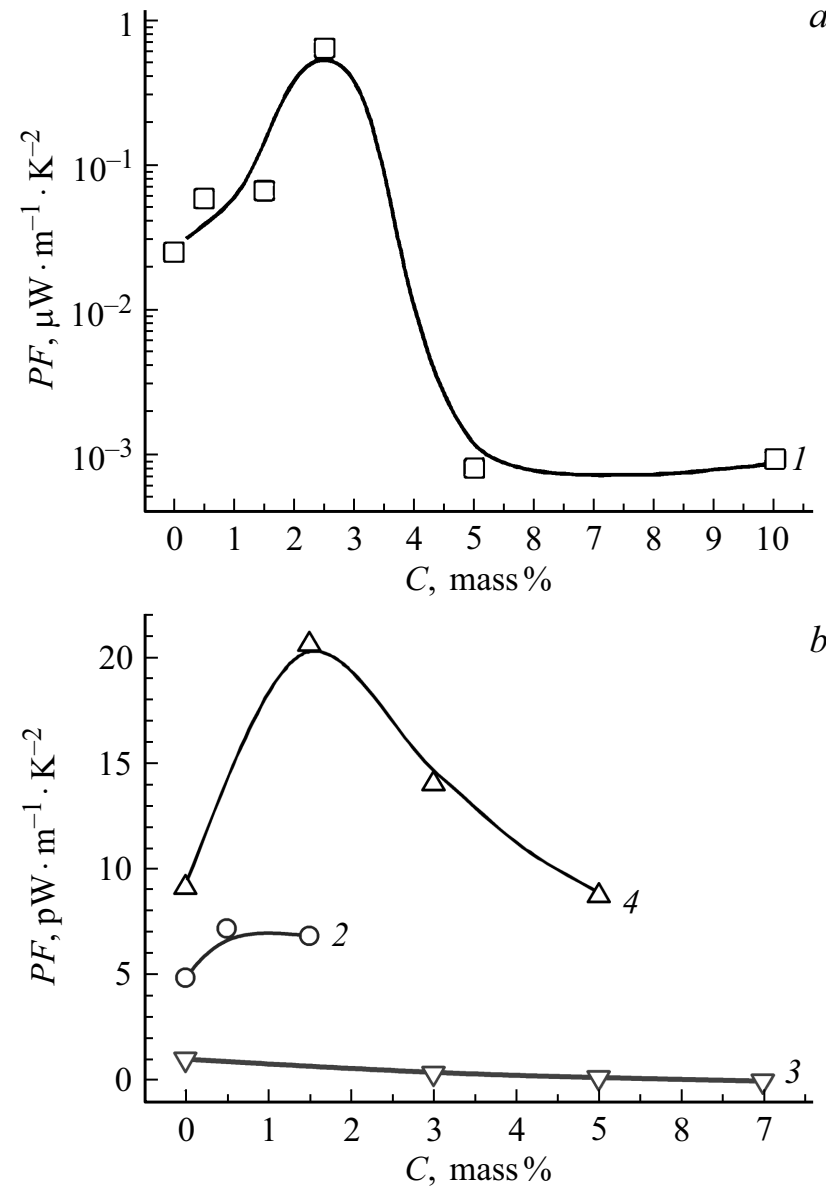

Рис. 3. Зависимости фактора термоэлектрической мощности от содержания углеродного наполнителя для композитов $\mathrm{Cu}_{n} \mathrm{O}-\mathrm{УH}$ с матрицей $\mathrm{Cu}_{2} \mathrm{O}(a)$ и наноразмерного $\mathrm{CuO}(b): 1-\left(\mathrm{Cu}_{2} \mathrm{O}_{\text {micro }}-\mathrm{YHM}\right)_{\mathrm{DBM}} ; 2-\left(\mathrm{CuO}_{\text {nano }}-\mathrm{YHM}\right)_{\mathrm{WBM}}$; $3-\left(\mathrm{CuO}_{\text {nano }}-\mathrm{YHB}\right)_{\mathrm{WBM}} ; 4-\left(\mathrm{CuO}_{\text {nano }}-\mathrm{YHB}\right)_{\text {USM }}$.

композитов $\left(\mathrm{CuO}_{\text {nano }}-\mathrm{VHB}\right)_{\text {USM }}$ примерно на порядок величины по сравнению с чистым $\mathrm{CuO}_{\text {nano }}\left(\mathrm{c} 4.9 \cdot 10^{4}\right.$ до $1.8 \cdot 10^{3} \Omega \cdot \mathrm{m}$ ), а термоэдс уменьшается на $28 \%$ (с 594 до $160 \mu \mathrm{V} / \mathrm{K}$ ). Порог протекания для системы $\left(\mathrm{CuO}_{\text {nano }}-\mathrm{VHB}\right)_{\text {USM }}$, определенный как середина участка наиболее значительного уменьшения $\rho$ и $S$, составил $\sim 1.5$ mass $\%$ УНВ.

Анализ представленных на рис. 2 зависимостей показал, что независимо от типа матрицы, наполнителя и их дисперсности величина удельного электрического сопротивления убывает сильнее с увеличением содержания углерода по сравнению с уменьшением значения термоэдс. Такая закономерность приводит к тому, что при концентрации УН, соответствующей порогу протекания, фактор термоэлектрической мощности, определяемый как $P F=S^{2} / \rho$ (где $S-$ значение термоэлектродвижущей силы, $\rho-$ удельное электрическое сопротивление материала), имеет ярко выраженный максимум (рис. 3). Исключением из этого правила являются образцы $\left(\mathrm{CuO}_{\text {nano }}-\mathrm{VHB}\right)_{\text {wвM }}$, для которых добавление 
углеродного наполнителя влияет на величину $\rho$ слабее остальных вследствие деструкции УНВ (кривая 3, рис. $3, b)$.

Сравнительный анализ полученных зависимостей показал, что самые большие значения фактора мощности среди изученных композитов обнаружены для образцов $\left(\mathrm{Cu}_{2} \mathrm{O}_{\text {micro }}-\mathrm{УHM}\right)_{\text {DвM. }}$ Максимальное значение фактора термоэлектрической мощности $P F=0.7 \mu \mathrm{W} \cdot \mathrm{m}^{-1} \cdot \mathrm{K}^{-2}$ было обнаружено для образца с концентрацией УН, соответствующей порогу протекания -2.5 mass \% УНМ (рис. 3,a). Полученные значения фактора мощности примерно на порядок ниже соответствующей величины, реализуемой в традиционных термоэлектрических материалах [20].

При использовании в качестве матрицы более высокоомного оксида $\mathrm{CuO}$ значения фактора термоэлектрической мощности, независимо от типа наполнителя, оказались меньше, чем в композитах с матрицей $\mathrm{Cu}_{2} \mathrm{O}$, почти на три порядка величины (рис. 3, $b$ ). Зависимости $P F \propto f([\mathrm{C}])$ для образцов $\left(\mathrm{CuO}_{\text {nano }}-\mathrm{УHM}\right)_{\mathrm{WBM}}$ и $\left(\mathrm{CuO}_{\text {nano }}-\mathrm{YHB}\right)_{\text {USM }}$ также имеют максимум при концентраци УН, соответствующих порогам протекания: 0.7 и 1.5 mass $\%$ (кривые 2 и 4 , рис. $3, b$ ).

Полученные значения фактора термоэлектрической мощности для всех исследованных композитов $\mathrm{Cu}_{n} \mathrm{O}-\mathrm{УH} \quad(n=1,2), \quad$ к сожалению, даже при оптимальном содержании УН являются очень низкими для практического применения, однако сам подход к модифицированию термоэлектрических свойств материала электропроводящими углеродными наночастицами выглядит весьма перспективным. Для этого необходимо добиться равномерного распределения УН.

3.2. Низкотемпературные зависимости электрических свойств объемных композитов оксид меди-углеродный наполнитель. Чтобы установить влияние углеродного наполнителя на особенности электропереноса полученных композитов, были исследованы температурные зависимости электрического сопротивления и термоэдс в диапазоне температур $77-300 \mathrm{~K}$.

Зависимости удельного электрического сопротивления от температуры в области $77-300 \mathrm{~K}$ для всех полученных образцов характеризуются отрицательным температурным коэффициентом, характерным для полупроводниковых материалов.

Температурные зависимости термоэдс композитов $\left(\mathrm{Cu}_{2} \mathrm{O}_{\text {micro }}-\mathrm{УHM}\right)_{\text {DBM }}$ с концентрацией УН до и после порога протекания различаются не только количественно, но и качественно. Для композитов до порога протекания термоэдс изменяется с температурой по кривой с максимумом, а абсолютные значения находятся на уровне не ниже $600 \mu \mathrm{V} / \mathrm{K}$. Для образцов с содержанием 5 и 10 mass\% УНМ величина термоэдс не превышает $12 \mu \mathrm{V} / \mathrm{K}$ и при понижении температуры практически линейно убывает. Таким образом, можно сделать вывод, что термоэлектрические свойства композитов $\left(\mathrm{Cu}_{2} \mathrm{O}_{\text {micro }}-\mathrm{УHM}\right)_{\text {DBм }}$ с концентрацией УНМ до порога
Таблица 3. Энергии активации проводимости $\left(E_{a}^{R}\right)$ и термоэдс $\left(E_{a}^{S}\right)$ композитов $\mathrm{Cu}_{2} \mathrm{O}-\mathrm{УH}$ с различным содержанием углеродного наполнителя

\begin{tabular}{c|c|c|c|c}
\hline Композит & С, mass $\%$ & $E_{a}^{R}, \mathrm{eV}$ & $E_{a}^{S}, \mathrm{eV}$ & $W_{h}, \mathrm{eV}$ \\
\hline & 0 & 0.500 & 0.500 & $\sim 0$ \\
$\left(\mathrm{Cu}_{2} \mathrm{O}_{\text {micro }}-\text { УHM }\right)_{\text {DBM }}$ & 0.5 & 0.463 & 0.439 & 0.024 \\
& 1.5 & 0.420 & 0.374 & 0.046 \\
& 2.5 & 0.404 & 0.350 & 0.054 \\
\hline & 0 & 0.490 & 0.490 & $\sim 0$ \\
$\left(\mathrm{CuO}_{\text {nano }}-\mathrm{УHM}\right)_{\text {WBM }}$ & 0.5 & 0.469 & 0.360 & 0.109 \\
& 1.5 & 0.460 & 0.306 & 0.154 \\
\hline & 0 & 0.401 & - & - \\
$\left(\mathrm{CuO}_{\text {nano }}-\text { УHB }\right)_{\text {WBM }}$ & 3 & 0.373 & - & - \\
& 5 & 0.365 & - & - \\
& 7 & 0.343 & - & - \\
\hline & 0 & 0.340 & 0.340 & $\sim 0$ \\
$\left(\mathrm{CuO}_{\text {nano }}-\text { УHB }\right)_{\text {USM }}$ & 1.5 & 0.323 & 0.147 & 0.176 \\
& 3 & 0.315 & 0.062 & 0.253 \\
& 5 & 0.303 & 0.033 & 0.270
\end{tabular}

протекания определяются полупроводниковой матрицей оксида меди, а за порогом - свойствами углеродного волокна.

Термоэдс композитов $\left(\mathrm{CuO}_{\text {nano }}-\mathrm{УHM}\right)_{\text {Wвм }}$ и $\left(\mathrm{CuO}_{\text {nano }}-\mathrm{YHB}\right)_{\text {USM }}$, также как и для композитов $\left(\mathrm{Cu}_{2} \mathrm{O}_{\text {micro }}-\mathrm{УHM}\right)_{\text {DBM }}$ с концентрацией УНМ до порога протекания, убывает с ростом температуры. Зависимости $S \propto f(T)$ композитов $\left(\mathrm{CuO}_{\text {nano }}-\mathrm{УHB}\right)_{\text {WBM }}$ измерить при температурах ниже комнатной не удалось по причине высокого электросопротивления образцов.

Для установления механизмов электропереноса зависимости удельного электрического сопротивления от температуры были перестроены в координатах $\ln \rho \propto f\left(1 / T^{n}\right)$, где $n$ принимали значения $1 / 4,1 / 2$, $1, \ln \rho \propto f(\ln T)$ и $\ln \rho \propto f(\ln (\ln (T)))$, а зависимости термоэдс - в координатах $S \propto f(\ln T), S \propto f(1 / T)$ и $S \propto f(\sqrt{T})$. Анализ полученных результатов показал, что температурные зависимости удельного электрического сопротивления и термоэдс для всех композитов с концентрацией УН до порога протекания имеют участки, удовлетворительно спрямляющиеся в координатах $\ln \rho \propto f(1 / T)$ и $S \propto f(1 / T)$ (рис. 4).

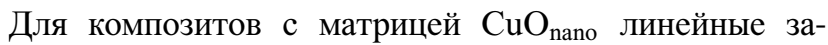
висимости $\ln \rho \propto f(1 / T)$ и $S \propto f(1 / T)$ наблюдаются при температурах 240-300 K (рис. 4, $c-g$ ). Для композитов $\left(\mathrm{Cu}_{2} \mathrm{O}_{\text {micro }}-\mathrm{УHM}\right)_{\text {Dвм }}$ с содержанием УНМ до порога протекания зависимость $S \propto f(1 / T)$ также спрямляется в интервале температур 240-300 K, однако зависимость $\ln \rho \propto f(1 / T)$ линейна во всем изученном диапазоне температур (рис. 4, $a, b$ ). Для композитов $\left(\mathrm{Cu}_{2} \mathrm{O}_{\text {micro }}-\mathrm{УHM}\right)_{\text {DBM, }}$ расположенных за порогом протекания, проводимость не является термоактивированной и определяется проводимостью углеродных волокон. 

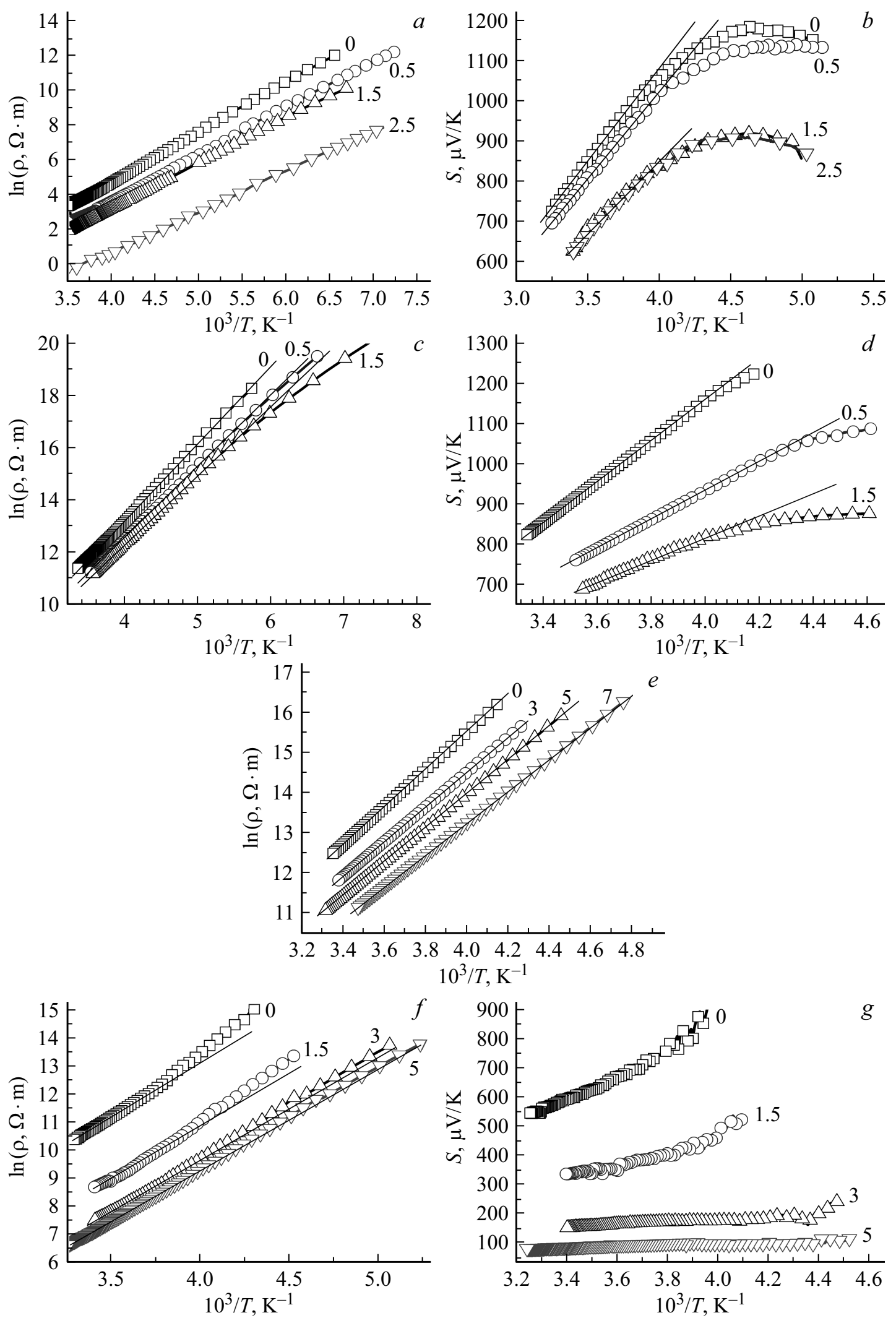

Рис. 4. Зависимости $\ln \rho \propto f(1 / T) \quad(a, c, e, f) \quad$ и $\quad S \propto f(1 / T) \quad(b, d, g)$ для $\quad$ композитов $\quad\left(\mathrm{Cu}_{2} \mathrm{O}_{\text {micro }}-\mathrm{УHM}\right)_{\mathrm{DBM}} \quad(a, b)$, $\left(\mathrm{CuO}_{\text {nano }}-\mathrm{YHM}\right)_{\text {wвм }}(c, d),\left(\mathrm{CuO}_{\text {nano }}-\mathrm{VHB}\right)_{\text {wвм }}(e),\left(\mathrm{CuO}_{\text {nano }}-\mathrm{VHB}\right)_{\text {USM }}(f, g)$. Цифрами около кривых указано содержание углеродного наполнителя в mass\%. 

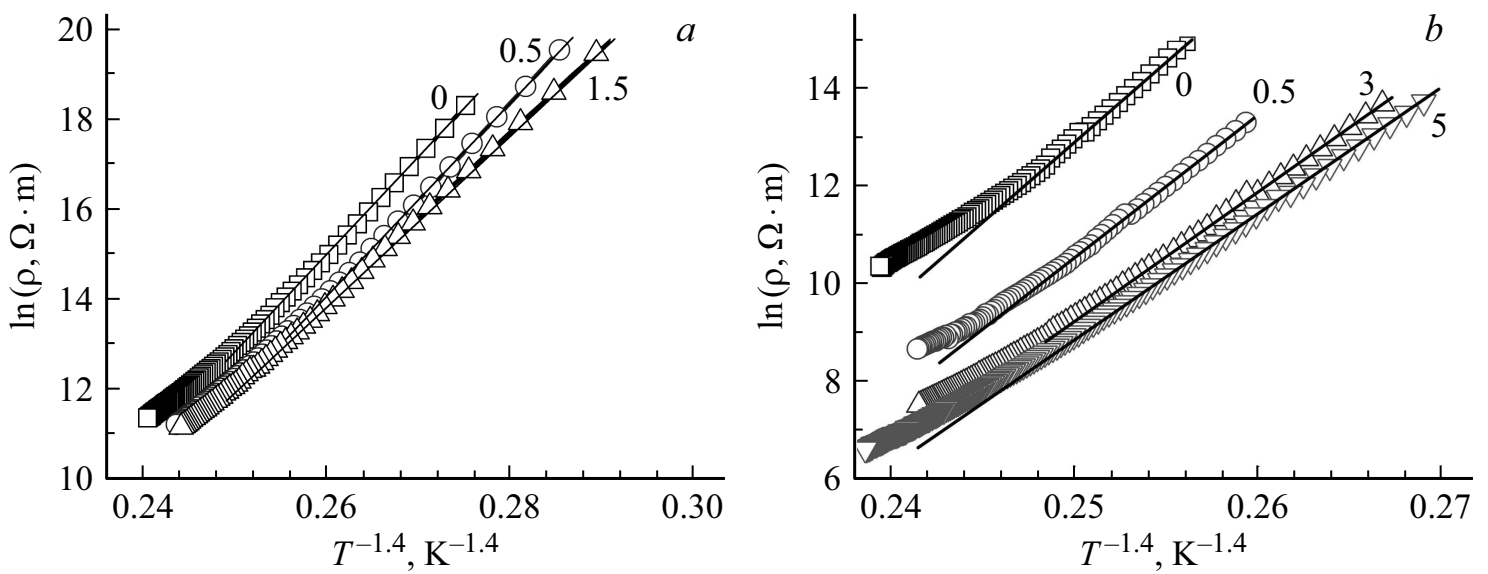

Рис. 5. Зависимости $\ln \rho \propto f\left(1 / T^{-1 / 4}\right)$ для композитов $\left(\mathrm{CuO}_{\text {nano }}-\mathrm{УHM}\right)_{\mathrm{WBM}}(a)$ и $\left(\mathrm{CuO}_{\text {nano }}-\mathrm{УHB}\right)_{\mathrm{USM}}(b)$. Цифрами около кривых указано содержание углеродного наполнителя в mass \%.

Если температурную зависимость электрического сопротивления исследованных композитов описать уравнением Аррениуса [21]

$$
\rho=\rho_{0} \exp \left(-\frac{E_{a}^{R}}{k T}\right),
$$

a термоэдс в этой же области температур формулой [21-23]

$$
S= \pm \frac{k}{e}\left(\frac{E_{a}^{S}}{k T}+A\right),
$$

где $E_{a}^{R}$ - энергия активации электрической проводимости; $k$ - постоянная Больцмана; $T$ - абсолютная температура; $e-$ заряд электрона; $A-$ постоянная; $E_{a}^{S}-$ энергия активации термоэдс, то по экспериментальным зависимостям (рис. 4) можно определить значения энергии активации проводимости $E_{a}^{R}$ и термоэдс $E_{a}^{S}$, которые приведены в табл. 3.

Анализ экспериментальных результатов (табл. 3) показал, что рассчитанные значения энергии активации $E_{a}^{R}$ и $E_{a}^{S}$ для образцов без углеродного наполнителя совпадают в пределах погрешности эксперимента и согласуются с приведенными в [24-26] данными для чистого $\mathrm{Cu}_{2} \mathrm{O}$ $(0.23-0.38 \mathrm{eV})$. При этом по литературным данным для поликристаллических полупроводников механизм проводимости определяется прыжковой проводимостью по локализованным состояниям вблизи валентной зоны (по границам зерен) или примесной проводимостью, где в качестве акцепторов выступают вакансии в подрешетке меди. Введение в $\mathrm{Cu}_{2} \mathrm{O}$ углеродного наполнителя для всех исследованных композитов приводит к уменьшению $E_{a}^{R}$ и $E_{a}^{S}$ и при увеличении углеродного наполнителя значения энергии активации электропроводности и термоэдс начинают различаться на некоторую величину $W_{h}$, растущую с увеличением в образцах содержания УН. Если принять за механизм проводимости в исследованных композитах прыжковый, то, согласно [21], различие в энергиях $E_{a}^{R}$ и $E_{a}^{S}$ может выступать в роли критерия определения прыжковой проводимости с переменной длиной прыжка по локализованным состояниям в хвосте валентной зоны. Тогда энергию $W_{h}$ можно интерпретировать как энергию прыжка, а формулу (1) будет более корректно переписать в виде

$$
\rho=\rho_{0} \exp \left(-\frac{E_{a}^{R^{*}}+W_{h}}{k T}\right),
$$

где $E_{a}^{R^{*}}=E_{a}^{S}=E_{B}-E_{\mathrm{F}}, E_{B}-$ энергия на краю валентной зоны; $E_{\mathrm{F}}$ - энергия Ферми. Достаточно большие значения $W_{h}$, полученные для исследованных композитов, вероятно, связаны с низкой плотностью локализованных состояний в хвосте валентной зоны. Если предположить, что перенос заряда лимитируется прыжками по границам зерен между вакансиями меди, то введение углеродного наполнителя приводит к увеличению расстояния между ними и, как следствие, к росту энергии активации прыжка.

Для композитов $\left(\mathrm{CuO}_{\text {nano }}-\mathrm{УHM}\right)_{\mathrm{WBM}}$ и $\left(\mathrm{CuO}_{\text {nano }}-\mathrm{УHB}\right)_{\text {USM }}$ при температурах ниже $240 \mathrm{~K}$ зависимости $\ln \rho \propto f(1 / T)$ отклоняются от линейной для всех образцов, включая чистый $\mathrm{CuO}_{\text {nano, }}$, что свидетельствует о смене механизма проводимости для этой системы, связанного с уменьшением кристаллитов до нанометровых величин. Такую структуру с высокой площадью межзеренных и межфазных границ можно считать квазиаморфной и использовать для анализа теорию переноса заряда для неупорядоченных твердых тел [21]. Анализ показал, что полученные результаты для композитов $\left(\mathrm{CuO}_{\text {nano }}-\mathrm{УHM}\right)_{\text {Wвм и }}\left(\mathrm{CuO}_{\text {nano }}-\mathrm{УHB}\right)_{\text {USM }}$ при температурах ниже $240 \mathrm{~K}$ могут быть достаточно хорошо описаны прямой линией в координатах $\ln \rho \propto f\left(1 / T^{1 / 4}\right)$ (рис. 5).

Если выполнение ,закона 1/4“ интерпретировать как прыжковую проводимость электронов с переменной длиной прыжка по локализованным состояниям, лежащим в узкой полосе энергий вблизи уровня Ферми, то, согласно работам Мотта [21], выражение для проводимости 
Таблица 4. Параметры композитов $\left(\mathrm{CuO}_{\text {nano }}-\mathrm{VHM}\right)_{\mathrm{WBM}}$ и $\left(\mathrm{CuO}_{\text {nano }}-\mathrm{VHB}\right)_{\mathrm{USM}}$, рассчитанные из модели прыжковой проводимости электронов с переменной длиной прыжка по локализованным состояниям, лежащим в узкой полосе энергий вблизи уровня Ферми

\begin{tabular}{c|c|c|c|c|c}
\hline Композит & $\mathrm{C}$, mass $\%$ & $B^{1 / 4}, \mathrm{~K}^{1 / 4}$ & $B, \mathrm{~K}$ & $g\left(E_{\mathrm{F}}\right), 1 /\left(\mathrm{eV} \cdot \mathrm{cm}^{3}\right)$ & $R$ при $200 \mathrm{~K}, \mathrm{~nm}$ \\
\hline & 0 & 325.33 & $1.120 \cdot 10^{10}$ & $1.245 \cdot 10^{19}$ & 3.569 \\
$\left(\mathrm{CuO}_{\text {nano }}-\mathrm{YHB}\right)_{\text {USM }}$ & 1.5 & 293.72 & $7.443 \cdot 10^{9}$ & $1.874 \cdot 10^{19}$ & 3.222 \\
& 3 & 262.56 & $4.752 \cdot 10^{9}$ & $2.935 \cdot 10^{19}$ & 2.880 \\
& 5 & 256.64 & $4.338 \cdot 10^{9}$ & $3.216 \cdot 10^{19}$ & 2.815 \\
$\left(\mathrm{CuO}_{\text {nano }}-\mathrm{YHM}\right)_{\text {WBM }}$ & 0 & 218.73 & $2.289 \cdot 10^{9}$ & $6.095 \cdot 10^{19}$ & 2.399 \\
& 0.5 & 210.61 & $1.968 \cdot 10^{9}$ & $7.090 \cdot 10^{19}$ & 2.310 \\
\end{tabular}

имеет вид, описываемый уравнением

$$
\sigma=e^{2} R^{2} v_{p h} g \exp \left(-\frac{B}{T}\right)^{1 / 4}
$$

где

$$
B=\frac{16}{a^{3} k g\left(E_{\mathrm{F}}\right)}
$$

и

$$
R=\left[\frac{3}{2 \pi a g\left(E_{\mathrm{F}}\right) k T}\right]^{1 / 4},
$$

$e$ - заряд электрона, $R$ - среднее расстояние прыжка, $v_{p h}$ - фактор спектра фононов взаимодействия, $T-$ абсолютная температура, $g\left(E_{\mathrm{F}}\right)$ - плотность состояний на уровне Ферми, $а$ - радиус локализации волновой функции электрона, $k$ - постоянная Больцмана.

Для подтверждения реализации данного механизма в композитах $\left(\mathrm{CuO}_{\text {nano }}-\text { УНM }\right)_{\text {WBм и }}\left(\mathrm{CuO}_{\text {nano }}-\text { УНB }\right)_{\text {USM }}$ в данном интервале температур желательно было бы измерить температурную зависимость термоэдс, которая при прыжковой проводимости электронов с переменной длиной прыжка по локализованным состояниям, лежащим в узкой полосе энергий вблизи уровня Ферми, должна удовлетворять зависимости $\alpha \sim \sqrt{T}$, однако вследствие высокого значения электрического сопротивления измерить ее не удалось.

Из экспериментальных данных по проводимости, используя уравнения (4)-(6), можно оценить эффективную плотность электронных состояний на уровне Ферми $g\left(E_{\mathrm{F}}\right)$. Если считать, что процесс проводимости лимитируется прыжками носителей заряда между частицами углеродного наполнителя, то, принимая радиус локализации электрона $a \approx 4 \mathrm{~nm}$ равным среднему радиусу частиц УН, были сделаны оценки значений переменной $B$ и плотности локализованных состояний на уровне Ферми для различных составов композитов, которые в среднем равны $g\left(E_{\mathrm{F}}\right) \approx 10^{16} \mathrm{eV}^{-1} \cdot \mathrm{cm}^{-3}$. В том случае, если процесс перескока атомов лимитируется прыжками электронов по катионным узлам кристаллической решетки, то за радиус локализации электрона нужно взять ковалентный радиус атома меди, т. е. $a \approx 0.11 \mathrm{~nm}$. В этом случае оценки плотности локализованных состояний на уровне Ферми для различных составов композитов дают значения $g\left(E_{\mathrm{F}}\right) \approx 10^{20} \mathrm{eV}^{-1} \cdot \mathrm{cm}^{-3}$ (табл. 4).

По-видимому, значения, полученные во втором случае, более реалистичны, поскольку в противном случае введение углеродного наполнителя приводило бы к снижению энергии прыжка при более высоких температурах (табл. 3). Следовательно, можно считать, что в области температур ниже $240 \mathrm{~K}$ электрическая проводимость композитов с матрицей из наноразмерного оксида меди $\mathrm{CuO}\left(\left(\mathrm{CuO}_{\text {nano }}-\text { УНM }\right)_{\text {Wвм и }}\left(\mathrm{CuO}_{\text {nano }}-\text { УНВ }\right)_{\text {USM }}\right)$ осуществляется прыжками носителей заряда с переменной длиной прыжка по локализованным состояниям, лежащим в узкой полосе энергий вблизи уровня Ферми, и лимитируется прыжками носителей по катионным узлам кристаллической решетки.

Хорошо известно, что электропроводность оксидных поликристаллических полупроводников определяется энергетическими состояниями, обусловленными дефектами на границах зерен [27,28]. Такие состояния являются локализованными, и перенос носителей заряда между ними при низких температурах осуществляется путем термоактивированного туннелирования от одного состояния к другому, что приводит к прыжковой проводимости между ближайшими соседними состояниями. Таким образом, полученные в табл. 4 оценки плотности локализованных состояний для образцов $\left(\mathrm{CuO}_{\text {nano }}-\mathrm{УHM}\right)_{\mathrm{WBM}}$ и $\left(\mathrm{CuO}_{\text {nano }}-\mathrm{VHB}\right)_{\text {USM }}$ без наполнителя можно отнести к плотности локализованных состояний, обусловленных дефектами на границах нанокристаллитов $\mathrm{CuO}$. Обработка в высокоэнергетической шаровой мельнице способствует образованию на поверхности порошинок $\mathrm{CuO}$ слоя, богатого дефектами. Поскольку температура спекания образцов подбиралась минимально возможной во избежание химического взаимодействия оксидной матрицы и углеродного наполнителя, то очевидно, что не все дефекты устранились во время спекания, что привело к увеличению значений плотности локализованных состояний в чистом $\mathrm{CuO}_{\text {nano, подвергнутом }}$ механической обработке в энергонапряженной мельнице по сравнению с $\mathrm{CuO}_{\text {nano }}$ после ультразвуковой (табл. 4).

На рис. 6 приведено схематическое изображение зонных диаграмм нанокристаллического оксида меди, 

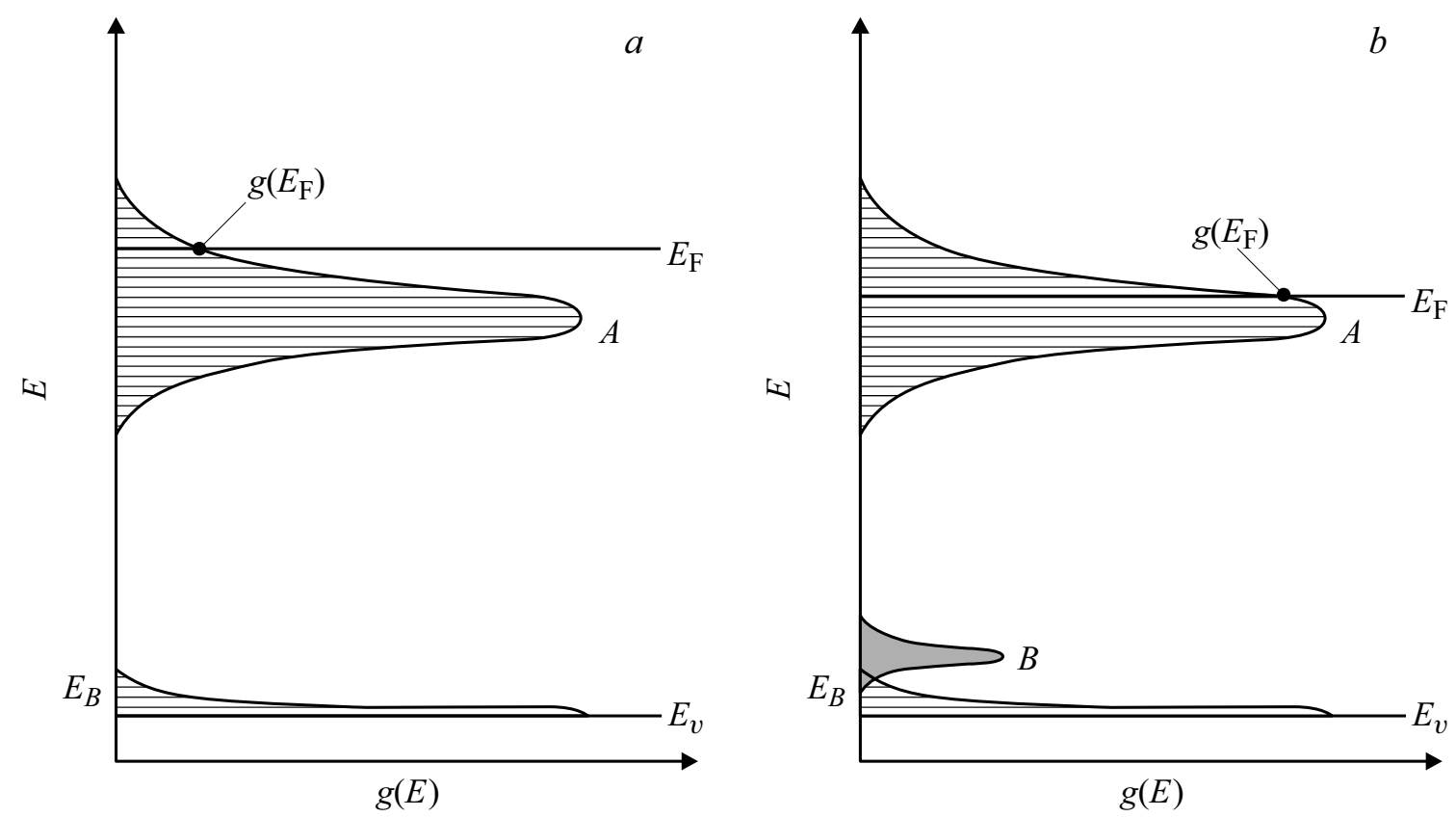

Рис. 6. Схематическое изображение зонных диаграмм нанокристаллического оксида меди без углеродного наполнителя (a) и нанокристаллического $\mathrm{CuO}$ с углеродным наполнителем $(b): A-$ область локализованных состояний, образованная дефектами на границах зерен $\mathrm{CuO}, \mathrm{B}$ - область локализованных состояний, образованная дефектами на границах $\mathrm{CuO}-\mathrm{УH}$.

объясняющее особенности электропереноса, которые наблюдаются в области низких температур для нанокристаллического $\mathrm{CuO}$ и композитов $\mathrm{Cu}_{n} \mathrm{O}-\mathrm{УH}(n=1,2)$. При температурах ниже $240 \mathrm{~K}$ электрическая проводимость нанокристаллического $\mathrm{CuO}$ и композитов на его основе осуществляется прыжками носителей заряда с переменной длиной прыжка по локализованным состояниям, лежащим в узкой полосе энергий вблизи уровня Ферми. Эти локализованные состояния обусловлены дефектами на границах нанокристаллитов $\mathrm{CuO}$ (область локализованных состояний $A$ на рис. 6).

При температурах, близких к комнатной, электрическая проводимость образцов $\left(\mathrm{CuO}_{\text {nano }}-\mathrm{УHM}\right)_{\mathrm{WBM}}$ и $\left(\mathrm{CuO}_{\text {nano }}-\mathrm{УHB}\right)_{\text {USM }}$ без наполнителя определяется носителями, возбужденными в делокализованные состояния в валентной зоне, что следует из совпадения энергий активации $\rho$ и $S$ (табл. 3). Тогда следует признать, что хвосты локализованных состояний в нанокристаллическом $\mathrm{CuO}$ простираются вглубь запрещенной зоны незначительно и становятся более глубокими, приближаясь к уровню Ферми при добавлении углеродного наполнителя (рис. $6, a$ ). В результате энергия активации проводимости при увеличении концентрации углеродного наполнителя понижается (табл. 3), а механизм проводимости при температурах вблизи комнатной меняется от прыжкового между ближайшими соседними состояниями (для чистого $\mathrm{CuO}$ ) к прыжковой проводимости с переменной длиной прыжка в хвосте валентной зоны (для композитов оксида меди с углеродным наполнителем).

Добавление углеродного наполнителя приводит к появлению в энергетическом спектре носителей заряда дополнительных локализованных состояний, связанных с дефектами, расположенными на границах раздела $\mathrm{CuO}$-углерод. Так как для композитов $\mathrm{CuO}_{\text {nano }}-\mathrm{УH}$ электрическая проводимость при температурах выше $240 \mathrm{~K}$ определяется прыжками в хвосте локализованных состояний на краю валентной зоны, то локализованные состояния дефектов на границах раздела $\mathrm{CuO}$-углерод должны быть расположены вблизи потолка валентной зоны оксида меди EV с перекрытием состояний в хвосте валентной зоны (область локализованных состояний $B$ на рис. $6, b)$. Такое предположение позволяет объяснить тот факт, что энергии активации проводимости и термоэдс при небольших концентрациях углерода практически равны энергиям активации чистых оксидов меди.

Увеличение плотности локализованных состояний вблизи уровня Ферми с увеличением содержании углеродного наполнителя (табл. 4) можно объяснить смещением $E_{\mathrm{F}}$ в области локализованных состояний в сторону потолка валентной зоны $E_{V}$, аналогично смещению для полупроводника при изменении степени легирования. Данный вывод согласуется с уменьшением энергий активации проводимости и термоэдс $\left(E_{a}^{R^{*}}=E_{a}^{S}=E_{B}-E_{\mathrm{F}}\right.$, $E_{B}-$ энергия на краю валентной зоны, $E_{\mathrm{F}}-$ энергия Ферми) с ростом доли УН в композите (табл. 3).

Таким образом, предложенная энергетическая зонная диаграмма рис. $6, b$ может качественно объяснить смену доминирующего механизма электропереноса с повышением температуры, а также влияние углеродного наполнителя на электрические свойства композитов $\mathrm{Cu}_{n} \mathrm{O}-\mathrm{УH}$. 


\section{4. Заключение}

1. Исследовано влияние углеродного наполнителя на электрическое сопротивление и термоэдс оксида меди. Установлено, что концентрационные зависимости удельного электрического сопротивления объемных композитов $\mathrm{Cu}_{n} \mathrm{O}-\mathrm{УH}$ характеризуются $S$-образными кривыми, типичными для перколяционных систем.

2. Показано, что независимо от типа матрицы, наполнителя и их дисперсности величина удельного электрического сопротивления убывает сильнее с увеличением содержания углерода по сравнению с уменьшением значения термоэдс. Такая закономерность приводит к тому, что в области порога протекания фактор термоэлектрической мощности имеет ярко выраженный максимум.

3. Исследования зависимостей удельного электрического сопротивления и термоэдс в области низких температур показали, что в диапазоне 240-300 К преобладающим механизмом электропереноса является термоактивационный. Анализ энергий активации удельной электрической проводимости и термоэдс показал, что добавление углеродного наполнителя приводит к появлению прыжковой проводимости с переменной длиной прыжка в хвосте валентной зоны, в то время как для образцов без углерода проводимость определяется прыжковой проводимостью между ближайшими соседями по границам зерен.

4. Для композитов с нанокристаллической матрицей $\mathrm{CuO}$ при температурах ниже $240 \mathrm{~K}$ наблюдается прыжковая проводимость с переменной длиной прыжка по локализованным состояниям матрицы, что связывается с проводимостью по межзеренным границам $\mathrm{CuO}$. Добавление углерода приводит к появлению в энергетическом спектре носителей заряда дополнительных состояний, расположенных вблизи потолка валентной зоны и связанных с границами раздела $\mathrm{CuO-углерод.} \mathrm{Это} \mathrm{объяс-}$ няет появление прыжковой проводимости с переменной длиной прыжка в хвосте валентной зоны и изменение плотности локализованных состояний на уровне Ферми при увеличении содержания УН в композите.

\section{Список литературы}

[1] S. Riffat, X. Ma. Appl. Thermal Eng. 23, 913 (2003).

[2] J.P. Heremans. Acta Phys. Polonica A 108, 609 (2005).

[3] Y. Ezzahri, G. Zeng, K. Fukutani, Z. Bian, A.A. Shakouri. J. Microelectronics 39, 981 (2008).

[4] R. Venkatasubramanian, E. Siivola, T. Colpitts, B. O'Quinn. Nature 431, 597 (2001).

[5] R. Venkatasubramanian, T. Colpitts, E. Watko, M. Lamvik, N. El-Masry. J. Cryst. Growth 170, 721 (1997).

[6] R. Funahashi, I. Matsubara. Appl. Phys. Lett. 79, 362 (2001).

[7] Л.П. Булат, Д.А. Пшенай-Северин. ФТТ 52, 452 (2010).

[8] H. Lin, E.S. Bozin, S.1. Billinge, L.E. Quarez, M. G. Kanatzidis. Phys. Rev. B 72, 1 (2005).

[9] T. Harman, P. Taylor, M. Walsh, B. LaForge. Science 297, 2229 (2002).

[10] A. Tavkhelidze. Nanotechnology 20, 6 (2009).
[11] A. Boukai, Y. Bunimovich, J. Tahir-Kheli, J-K Yu, W. Goddard, J. Heath. Nature Lett. 451, 168 (2008).

[12] A. Hochbaum, R. Chen, R. Delgado, W. Liang, E. Garnett, M. Najarian, A. Majumdar, P. Yang. Nature Lett. 451, 163 (2008).

[13] J. Keyani, A.M. Stacy. Appl. Phys. Lett. 89, 233106 (2006).

[14] А.В. Шевельков. Успехи химии 77, 3 (2008).

[15] С.В. Мищенко, А.Г. Ткачев. Углеродные наноматериалы. Производство, свойства, применение. Машиностроение, М. (2008). 320 c.

[16] Ю.В. Панин, Ю.П. Прилепо, В.А. Макагонов, С.А. Солдатенко. Альтернативная энергетика и экология 7, 64 (2011).

[17] Ю.Ю. Тарасевич. Перколяция: теория, приложения, алгоритмы. УРСС, М. (2002). 112 c.

[18] С.А. Гриднев, Ю.Е. Калинин, А.В. Ситников, О.В. Стогней. Нелинейные явления в нано- и микрогетерогенных системах. БИНОМ, Лаборатория знаний, М. (2012). 352 с.

[19] A. Combessis, L. Bayon, L. Flandin. Appl. Phys. Lett. 102, 011907 (2013).

[20] Б.С. Поздняков, Е.А. Коптелов. Термоэлектрическая энергетика. Атомиздат, М. (1974). 264 с.

[21] Н.Ф. Мотт, Э.А. Дэвис. Электронные процессы в некристаллических веществах. Мир, М. (1982). Т. 1. 658 с.

[22] О.Е. Парфенов, Ф.А. Шклярук. ФТП 41, 1041 (2007).

[23] Б.И. Шкловский, А.Л. Эфрос. Электронные свойства легированных полупроводников. Наука, М. (1979). 416 с.

[24] A.P. Young, C.M. Schwartz. J. Phys. Chem. Solids. 30, 249 (1969).

[25] Г. Буш. УФН 6, 258 (1952).

[26] E. Fortunato, V. Figueiredo, P. Barquinha, E. Elamuruguetal. Appl. Phys. Lett. 96, 192102 (2010).

[27] F. Greuter, G. Blatter. Semiconductor Sci. Technology 5, 111 (1999).

[28] K. Ellmer, R. Mientus. Thin Solid Films 516, 4620 (2008). 